\title{
Modification of Motor Output to Compensate for Unanticipated Load Conditions During Rapid Voluntary Movements
}

\author{
R.G. Lee, G.E. Lucier, B.E. Mustard and D.G. White
}

\begin{abstract}
Mechanisms responsible for load compensation during fast voluntary movements were investigated in 20 normal subjects trained to carry out rapid wrist flexions against a standard load. When an unanticipated increase in load occurred, there was a compensatory increase in agonist EMG and decrease in antagonist EMG. Unanticipated decreases in load produced reciprocal changes with a decrease in agonist EMG and an increase in antagonist EMG. The latency of these EMG changes was quite short and compatible with a spinal reflex mechanism rather than a long loop response. The results suggest that mechanisms exist at the spinal level to allow rapid modification of motor programs when unanticipated load conditions are encountered on initiation of movement.
\end{abstract}

\begin{abstract}
RÉSUMÉ: Des modifications de la compensation motrice en réponse au poids non anticipé pendant des mouvements voluntaires rapides Les mécanismes responsables de la compensation pour le poids pendant les mouvements volontaires rapides ont été investigués chez 20 sujets normaux entraînés à exécuter rapidement des flexions du poignet contre un poids standard. Quand le poids fut augmenté soudainement avant l'initiation du mouvement, il se produisit une augmentation compensatoire de l'activité des agonistes et une diminution de l'activité des antagonistes à l'EMG. Une diminution inattendue du poids produisit des changements réciproques avec une diminution de l'activité des agonistes et une augmentation de celle des antagonistes à l'EMG. La période de latence de ces changements électromyographiques fut assez courte et compatible avec un mecanisme réflexe de type spinal plutôt qu'avec une réponse de type boucle longue. Les résultats suggèrent qu'il existe au niveau spinal des mécanismes qui permettent des modifications rapides des programmes moteurs quand des variations imprévues de poids surviennent pendant les mouvements volontaires rapides.

Can. J. Neurol. Sci. 1986; 13:97.102
\end{abstract}

The extent to which motor programs controlling rapid voluntary movements can be modified by sensory feedback has been a topic of considerable debate. According to a hypothesis proposed a number of years ago by Kornhuber, ' voluntary movements of the extremities can be subdivided into two major categories - ramp movements and ballistic movements. Ramp movements, such as those used to track a moving visual target, are relatively slow and utilize continuous sensory feedback. Ballistic movements are much faster and in Kornhuber's view, occur too rapidly to allow any opportunity for modification of the motor output by sensory feedback and reflex mechanisms.

Although this was an attractive hypothesis, it has become clear that it represents an oversimplification. There are obvious differences between very fast and very slow movements, but many types of voluntary movements fall between these two extremes. The dividing line between ballistic and ramp movements is indistinct and it now seems unlikely that limb move- ments can be interpreted in the same manner as eye movements, where separate control systems exist for saccadic and pursuit movements. Also, there has not been universal agreement as to exactly what constitutes a "ballistic" movement. Some investigators have used the term to describe rapid movements which require the subject to stop at a specific end-point. These selfterminated movements obviously require a different set of central commands from those which control rapid movements in which there is no intent to stop.

Experiments designed to test whether reflex mechanisms are operative during very rapid movements have yielded somewhat conflicting results. ${ }^{2-5}$ The present study was designed to answer two questions relevant to this problem. First, if a subject learns to perform a very fast movement against a standard load, is the motor output (as determined from the EMG signals) modified if an unexpected change in load occurs prior to the onset of the movement? Secondly, if there is evidence of load 
compensation in this situation, does it occur at a time which would indicate participation by spinal reflexes, or is it more delayed and compatible with feedback over long-loop pathways?

The results to be presented will show that compensation for unexpected changes in load does occur even during the fastest voluntary movements. The compensatory changes in EMG output occur at short latencies compatible with spinal reflex mechanisms. Some of these results have been published previously in a preliminary report. ${ }^{6}$

\section{Methods}

Twenty healthy volunteers ranging in age from 20 to 45 participated in these experiments. The subjects were trained to perform rapid flexion movements of the wrist over an arc of 40 degrees to align a cursor to a target displayed on an oscilloscope. They were instructed to move as rapidly as possible, but were required to terminate the movement at the spot indicated by the target. Trials which were not completed within $100 \mathrm{msec}$. of the onset of the movement were not included in the analysis. Therefore the mean velocity for these movements was not less than 400 degrees/second.

The forearm was immobilized in a manipulandum which restricted movements to the wrist joint. A steady load which opposed the movement was generated by a torque motor (Aeroflex TO $82 \mathrm{~W})$. When the subject relaxed prior to initiating movement, the load on the handle caused it to rest firmly against a mechanical stop. A microswitch in this stop was released as soon as each movement commenced and provided a trigger signal for averaging of repeated trials.

EMG activity was recorded from the flexor carpi radialis and extensor carpi ulnaris muscles with closely spaced surface electrodes (interelectrode distance $3 \mathrm{~cm}$.). The EMG signals were rectified and averaged using a PDP $11-40$ computer system. Wrist position was monitored by a precision potentiometer and velocity of movement was obtained by digital differentiation of the position signal. The forces occurring during the movement were recorded with a torque transducer.

In the initial set of experiments, a standard load of 0.25 Newton-meters (NM) was used. After the subject had carried out at least 50 practice movements against this small standard load, the load was increased prior to the onset of movement for a small percentage (less than $20 \%$ ) of randomly selected trials. Since the load change occurred while the handle was resting against the mechanical stop, the subjects had no indication that conditions had been altered until they actually commenced the movement. In a second set of experiments, the practice movements were carried out against the larger load which was then decreased on random trials.

The EMG signals, handle position, and torque for movements made against the unexpected loads were averaged separately and compared with the responses associated with movements against the standard expected load. A computer program was developed to allow simultaneous display of two averaged responses which could be superimposed to permit measurement of the timing and size of the EMG responses and the point at which the two signals diverged.

\section{RESUlts}

\section{Effect of Unexpected Increases in Load}

For movements made against the smaller loads, there was a characteristic triphasic EMG pattern consisting of an initial burst of activity from the agonists (wrist flexors) followed by a silent period and then a second agonist burst. In the antagonist muscle, there was usually a single EMG burst which commenced part way through the agonist burst and continued during the silent period between the first and second agonist bursts. In some subjects a second smaller EMG burst from the antagonist muscle occurred.

Figure 1 compares the results from one subject for movements against the small expected load with the recordings obtained for movements made against an unexpected large load. The position and velocity traces indicate that the movements against the larger load occurred at a slightly reduced velocity and the time for final acquisition of the target was delayed. The initial EMG burst from the agonist was identical in the two situations, an observation which was not unexpected since the motor commands should have been the same in each case. However, when the unexpected large load was encountered there was an increase in the agonist EMG which started near the end of the first agonist burst and continued through the period that normally would have been silent between the first

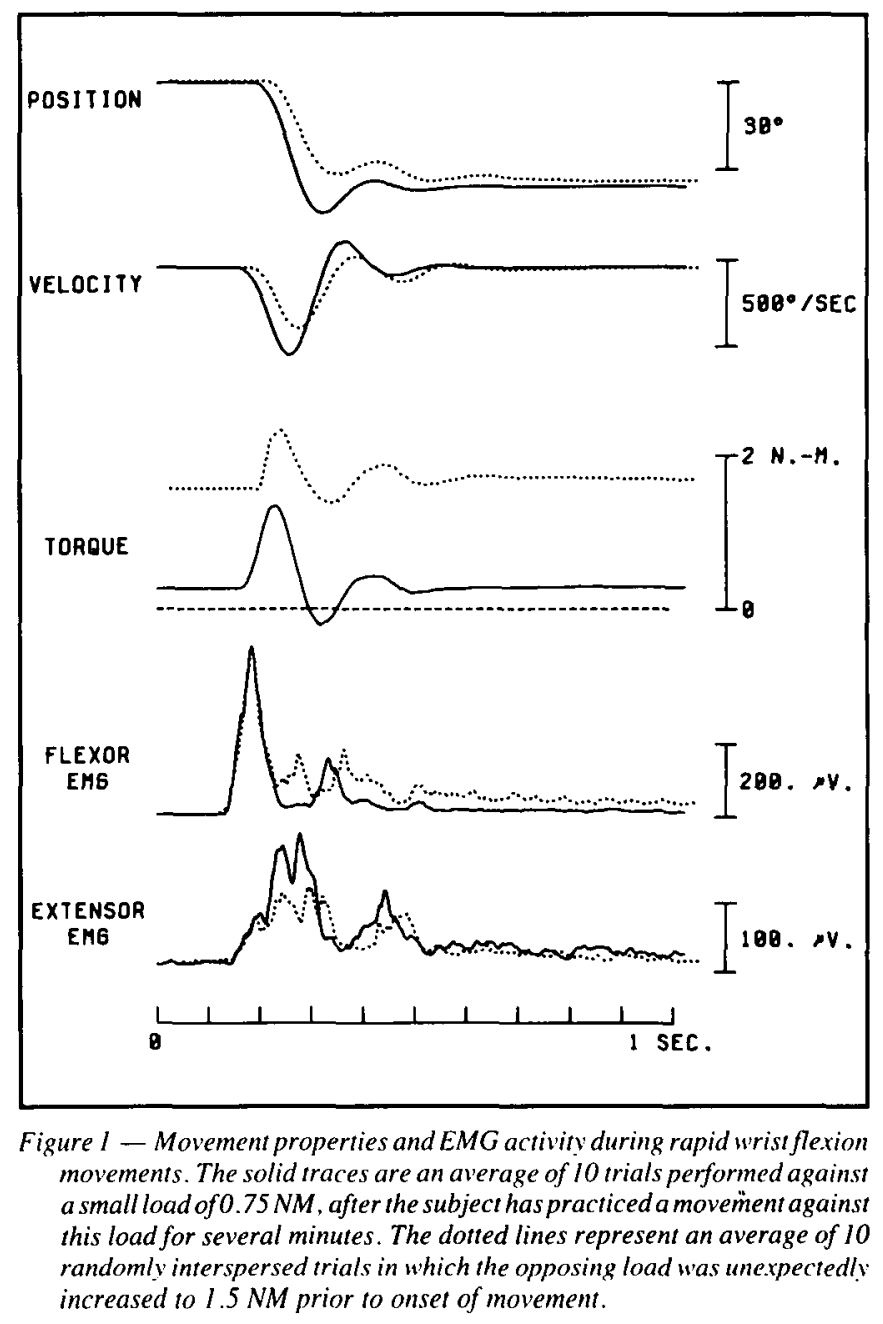


and second bursts. In the example shown in Figure 1, the second agonist burst is slightly delayed in the situation where the movement occurred against a larger load. The subsequent part of the EMG recording shows an increased level of tonic EMG activity since the subject was required to hold the handle in the target zone against the larger load. The extensor EMG recordings show a decrease in antagonist EMG output which commences at almost exactly the same time as the compensatory increase in agonist EMG.

These experiments were repeated for a number of different load increments. The amount of additional EMG activity generated by the agonist muscle for movements against the unanticipated large load was plotted as a function of the amount by which the load was increased above the expected baseline level (Figure 2). For 20 subjects there was a clear monotonic relationship between these variables; the larger the load increment, the greater the compensatory increase in EMG. Similarly, the amount by which the antagonist EMG burst decreased varied in relation to the size of the load increment.

\section{Timing of Compensatory EMG Changes}

Unlike experiments in which load perturbations are applied, there was no precise time at which the stimulus was delivered. We therefore attempted to determine the earliest time at which afferent activity might commence to signal that the load had been changed (Figure 3). As discussed previously, the mechanical stop prevented the subject from detecting any change in load during the waiting period prior to movement. Using the position trace and taking the first point at which detectable

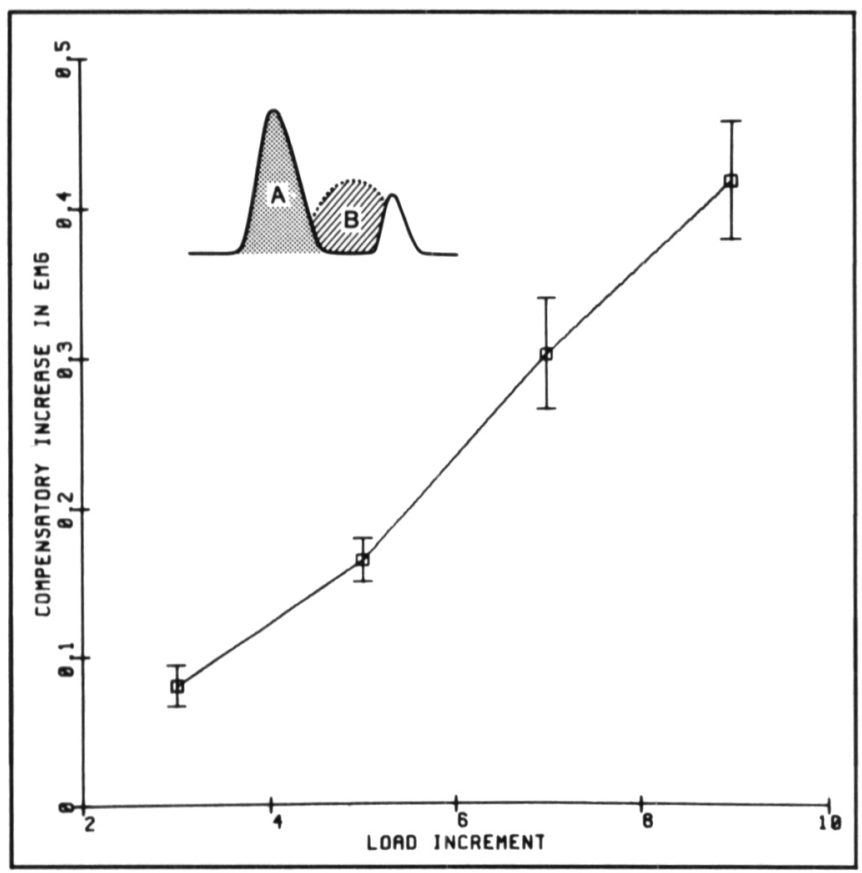

Figure 2 - Relationship between increment in load and the amount of additional EMG activity from agonist muscle during movements against unexpected large loads. Values on abscissa represent the factor by which load was increased above the standard level used during control of trials. Ordinate values were obtained by measuring the areas of the first agonist burst $(A)$ and the additional EMG activity for movements against larger loads $(B)$. and then calculating a ratio B/A (see inset). Values shown represent means \pm S.E. for 20 subjects. movement occurred as a reference point, the latency to the onset of the compensatory increase in agonist EMG activity for the 20 subjects was $29.6 \pm 3.4$ ( $\mathrm{SE}$ ) msec. However, as illustrated schematically in Figure 3, the increase in torque associated with contraction of the agonist muscles begins shortly before any actual movement. It is likely that afferent signals indicating the amount of opposing load occur as soon as forces are generated by the muscle contraction. These could originate from Golgi tendon organs or possibly from cutaneous receptors. The time from the onset of the torque change to the compensatory increase in agonist EMG activity was $46.1 \pm 3.6 \mathrm{msec}$. This is probably an overestimation of the actual latency, however, because when the torque signals for the two load conditions were superimposed, they did not diverge until at least $10 \mathrm{msec}$. after the torque began to rise above the baseline level. We also measured the time from onset of the first agonist EMG burst to the beginning of the compensatory increase in EMG activity. This was $108.2 \pm 4.0 \mathrm{msec}$. However, as shown in Figure 1, the initial EMG burst was almost identical in the two conditions so it is unlikely that information concerning the increase in load could be generated during the first part of the agonist burst.

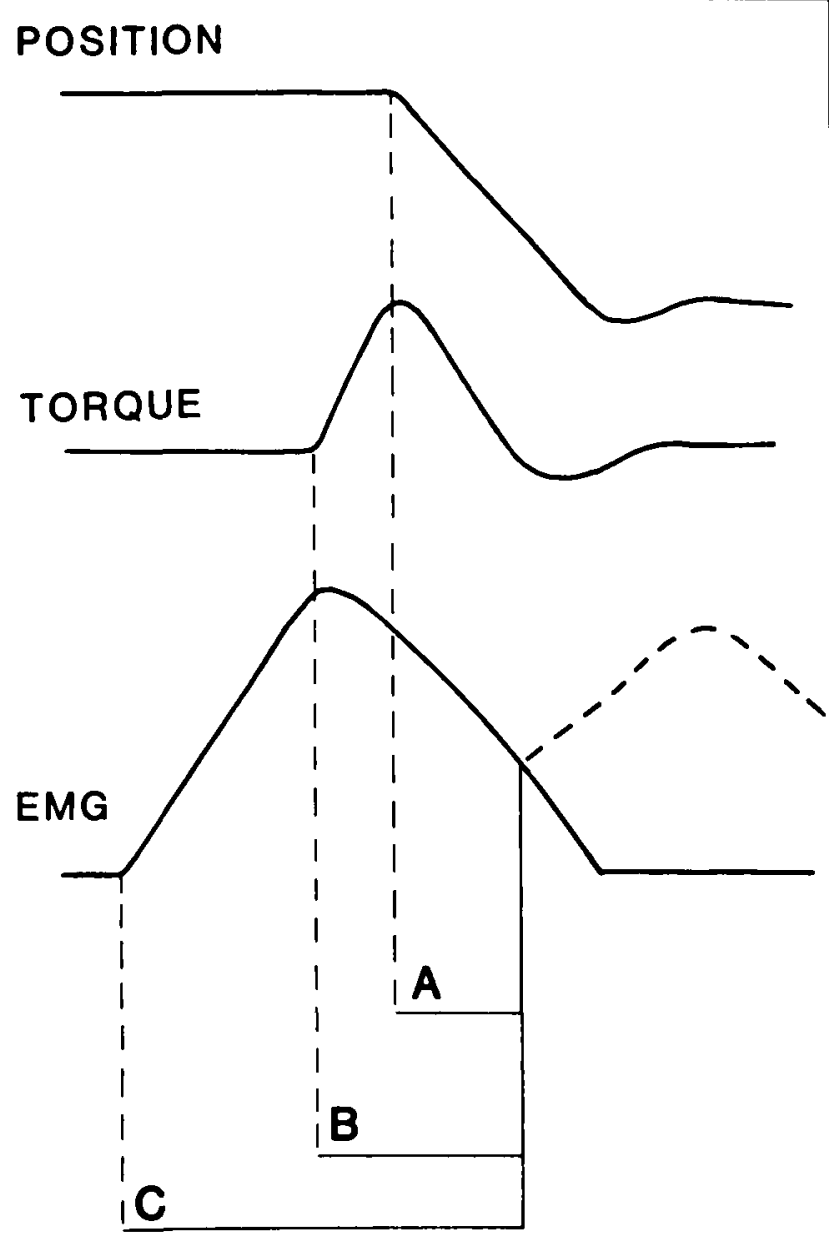

Figure 3 - Schematic illustration of measurements made to determine the latency of the compensatory increase in agonist EMG when movements were performed against unexpected large loads. Mean latencies and standard errors for 20 subjects were:

A. (from onset of movement) $29.6 \pm 3.4 \mathrm{msec}$.

$B$. (from onset of torque change) $46.1 \pm 3.6 \mathrm{msec}$

C. (from onset of agonist EMG burst) $108.2 \pm 4.0 \mathrm{msec}$. 


\section{Effect of an Unexpected Decrease in Load}

Figure 4 shows the changes in agonist and antagonist EMG bursts when the load was unexpectedly decreased after the subject had learned to perform the movement against a larger load than what was used in the initial experiments. In this example, the solid lines represent the averaged responses for movements against a load of 1.6 NM. During the trials represented by the dotted lines the load was unexpectedly decreased to $0.25 \mathrm{NM}$. With the larger load the silent period between the first and second agonist bursts was not so well defined. When the load was less than what was expected by the subject, there was a compensatory decrease in agonist EMG activity and a corresponding increase in antagonist EMG amplitude. There was also an increase in the duration of the antagonist burst. The compensatory changes detected in the EMG bursts occurred at almost exactly the same time in relation to the onset of movement as had been observed for the movements against unexpected load increases.

\section{Discussion}

The major observation from this study is that the EMG bursts associated with rapid learned movements can be modified at relatively short latencies when unexpected load changes are introduced prior to onset of movement. A number of investigators have studied the EMG patterns which generate rapid

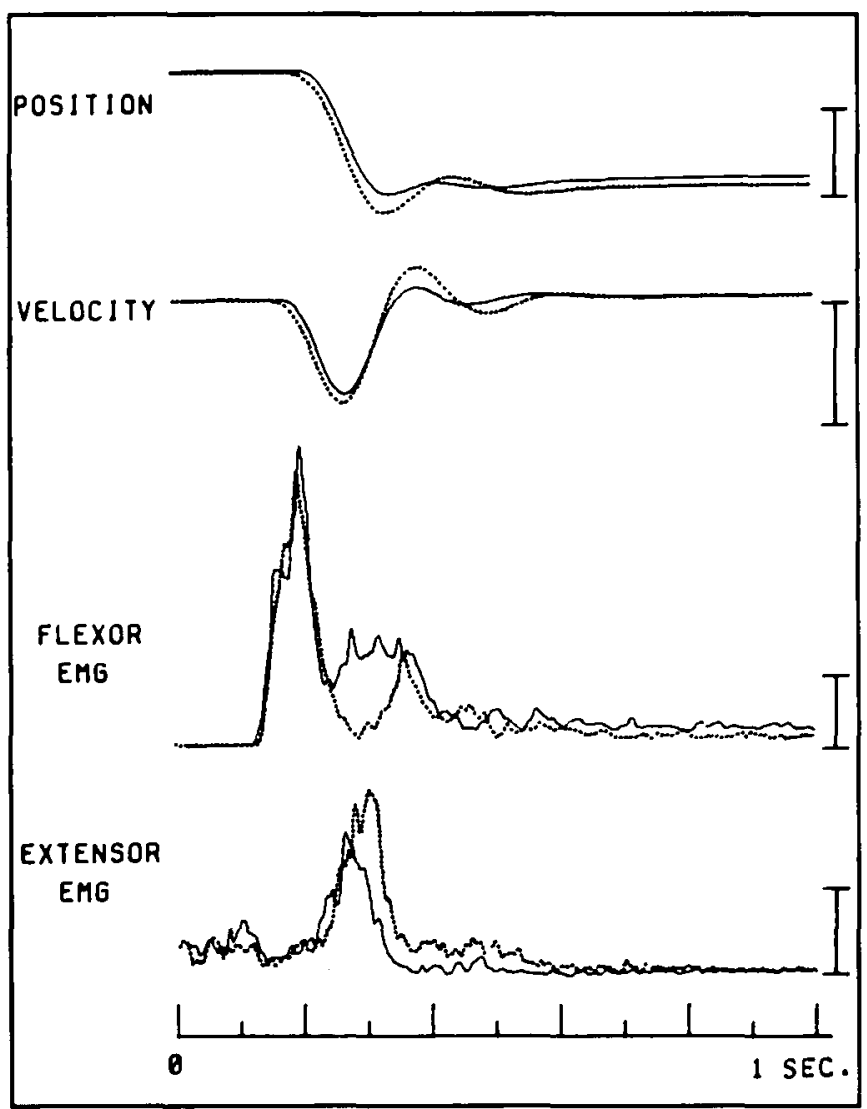

Figure 4-Effect of an unexpected decrease in load prior to rapid wrist flexion movements. Solid traces represent movements made against a standard load of 1.5 NM; dotred traces represent movements against an unexpected smaller load of $0.25 \mathrm{NM}$. Calibrations: Position $30^{\circ}$, Velocity $500 \% \mathrm{sec}$, EMG $100 \mathrm{uV}$. voluntary movements. ${ }^{2.4 .7 .12}$ Lestienne $^{\prime \prime}$ observed that for movements occurring at the same velocity, increases in the inertial load caused an increase in the magnitude of the EMG bursts from both agonist and antagonist muscles, but did not change the timing of the bursts. More recently, Benecke et al ${ }^{12}$ have reported complex interactions between changes in amplitude of movement and inertial load which result in modifications of the size and timing of the EMG bursts.

Although it has been proposed that ballistic movements occur too rapidly to be modified by sensory feedback, ${ }^{1.7}$ there is experimental evidence that some types of centrally programmed movements can be modified by changes in the opposing load or other external conditions. ${ }^{13.14}$ The effects of unexpected load perturbations during voluntary movements at different velocities have been studied by Desmedt and Godaux. ${ }^{2}$ During relatively slow ramp movements of the index finger, sudden increases in the opposing load produced an increase in agonist EMG activity after a latency of $52 \mathrm{msec}$. This timing is comparable to that of the long latency component of the stretch reflex which may be mediated by a long-loop transcortical feedback pathway. ${ }^{15.16}$ However, when similar perturbations occurred during very rapid movements, the earliest change in EMG activity did not occur until $130 \mathrm{msec}$. or more after the perturbation. Clearly, reflex mechanisms were not operating to provide load compensation in this situation, although an increase in EMG output corresponding to a long latency reflex was present if the load perturbation occurred very early during the task prior to the actual onset of movement.

The role of stretch reflexes during movement at the elbow joint has been investigated by Cooke. ${ }^{5}$ When sudden perturbations were applied during the course of a voluntary movement, the reflex EMG response was much smaller during fast movements than during slow movements. It was suggested that reflexes occurring during movement acted to re-establish the trajectory of the limb which had been altered by the perturbation. Dufresne et $\mathrm{al}^{3}$ examined changes in biceps EMG in response to sudden load increases during voluntary flexion of the elbow. They observed compensatory increases in EMG output which did not seem to depend on the velocity of movement, although the exact timing of these responses was difficult to determine from their published data. Hallett and Marsden ${ }^{4}$ studied the effect of load perturbations applied during rapid flexions of the human thumb. When these perturbations were sufficient to either halt or reverse the movement, there was a definite accentuation of the second agonist EMG burst. In some cases, there was also a reflex EMG response between the first and second agonist bursts occurring about $45 \mathrm{msec}$. after the onset of the perturbation. In a subsequent study from the same laboratory, ${ }^{17}$ it was concluded that long latency stretch reflexes are responsible for automatic compensation for unexpected load changes during movements of the human thumb.

Our approach differed from previous studies in that the load changes occurred prior to the onset of movement and were applied in a manner which did not result in any displacement of the joint or stretch of the muscle. The motor program controlling the movement would have been initiated well before the subject received any sensory feedback indicating that the load had been altered. Brown and Cooke ${ }^{18}$ have also examined the effect of load changes which precede voluntary movements. They did not observe any apparent reflex activity during the 20-80 msec. period following the perturbation and suggested 
that this might be due to the fact that peripheral inputs were being gated out at this time. However, they did observe an increase in EMG activity during the later part of the first agonist burst, a modulation which seemed to occur at a fixed time following the onset of the initial agonist burst even when the perturbation occurred at variable times preceding this EMG burst.

Mortimer et al ${ }^{19}$ studied stretch reflexes during the reaction time between a signal to move and the onset of voluntary contraction. They observed an increase in the gain of the long latency reflex prior to voluntary movement but no change in the short latency spinal component of the reflex. However, Day et $\mathrm{al}^{20}$ were unable to confirm these results in a similar experiment, and they concluded that there was little change in the size of the long latency reflex prior to voluntary movement.

The compensatory EMG changes which we have observed occurred at latencies shorter than what would be expected if they were mediated by long-loop or supraspinal reflexes. The increase in agonist EMG during movements against unexpected large loads occurred within $30 \mathrm{msec}$. of the onset of movement. Even allowing for the fact that afferent activity from cutaneous receptors or Golgi tendon organs could have signalled an increase in load a few msec. before actual movement occurred it seems likely that these compensatory changes are mediated by mechanisms acting at the spinal level. It is difficult to conceive how afferent discharges beginning prior to the point at which the torque signals diverge would be different for movement against the expected and unexpected loads.

Before discussing the mechanisms responsible for this short latency compensatory increase in agonist EMG activity, we should consider the origin and nature of the afferent input generated by the change in load. This is not a stretch reflex in the usual sense since it occurs at a time when the muscle is still being shortened when we would expect the spindles to be at least partially unloaded. Golgi tendon organs, which are sensitive to small changes in tension, are activated when the muscle contracts and the level of activation is probably greater when the opposing load is increased. However, our present under-

1. CONTRACTION AGAINST STANDARD ANTICIPATED LOAD

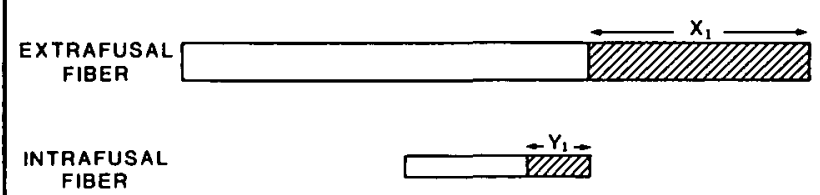

2. CONTRACTION AGAINST UNEXPECTED LARGE LOAD

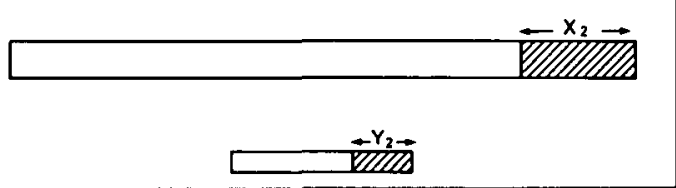

Figure 5 - Schematic representation of proposed mechanism for compensatory changes occurring during movements against unexpected large loads. $X I$ and $Y I$ represent the amount of shortening which occurs in extrafusal and intrafusal muscle fibers during contraction against a standard load. $X 2$ and $Y 2$ are the corresponding values when the load is larger than expected. Note the mismatch between intrafusal and extrafusal fiber length: $Y 2=Y 1, X 2<X 1$ standing of Golgi tendon organs is that they inhibit motoneurons for the muscle from which they originate, ${ }^{21}$ so it seems unlikely that they could be responsible for the increased EMG activity in the agonist muscle.

It is more probable that spindle primary endings and IA afferents are providing the information which results in increased motoneuron output during movements against unexpected large loads. A tentative mechanism for this is illustrated schematically in Figure 5 which shows the relationship between intrafusal and extrafusal fiber length. During the learned tasks against the standard load extrafusal fibers shorten by an amount indicated by $X 1$. Because of alpha-gamma co-activation, there is simultaneous shortening of intrafusal fibers, indicated in Figure 5 by Y1. When the subject encounters a load which is larger than what was expected, the velocity of the movement is reduced (see Figure 1), and at a given point during the movement the amount of shortening of extrafusal fibers is less than what it was under the standard conditions (i.e. X2 X1). However, since the central command which initiated the movement was the same in both situations, the amount of shortening of intrafusal fibers is not changed $(\mathrm{Y} 2=\mathrm{Y} 1)$. Thus, we have a situation in which there is a mismatch between intrafusal and extrafusal fiber length.

Although alpha-gamma co-activation does serve to prevent complete unloading of the spindles during voluntary contraction, it is not totally effective in this role. Recordings from spindle afferents indicate that there is some decrease in the afferent discharge during voluntary contraction and this change becomes more prominent with faster movements. ${ }^{22.23}$ Therefore, in the situation illustrated in Figure 5, there is less unloading of the spindles when the load is greater than what was anticipated. If the central command to alpha motoneurons is programmed to account for a decrease in afferent excitatory activity during contraction and this does not occur, then the effect would be comparable to what would take place if the muscle had actually been stretched - i.e. a short latency increase in motoneuron output. Similarly, the inhibitory effect on motoneurons for the antagonist muscle resulting from activation of $1 \mathrm{~A}$ inhibitory interneurons would be more than anticipated, and the result would be a decrease in the antagonist EMG burst. With unexpected decreases in opposing load, the opposite situation would occur. $X 2$ and $Y 2$ would be larger than $X 1$ and $Y 1$ respectively. But the unloading of spindles would be greater than what occurred during contractions against the standard load and the result would be a short latency decrease in agonist motoneuron output.

Our results suggest that even during very fast voluntary movements, mechanisms at the spinal level can cause rapid modification of motor output to compensate for load conditions which were not anticipated when the program controlling the movement was initiated. The functional role of the short latency spinal stretch reflex during voluntary movement has been debated for some time. Our studies provide evidence to suggest that these reflexes do participate in load compensation.

\section{ACKNOWLEDGEMENT}

This research was supported by the Medical Research Council of Canada and the Alberta Heritage Foundation for Medical Research. 


\section{REFERENCES}

1. Kornhuber HH. Motor functions of cerebellum and basal ganglia: The cerebello-cortical saccadic (ballistic) clock, the cerebellonuclear hold regulator, and the basal ganglia ramp (voluntary, speed smooth movements) generator. Kybernetik 1971;8: 157-162.

2. Desmedt JE, Godaux E. Ballistic skilled movements: Load compensation and patterning of the motor commands. In: Cerebral motor control in man: long loop mechanisms. Desmedt JE, ed. Prog clin Neurophysiol. Basel, Karger. 1978;4: 21-55.

3. Dufresne JR, Gurfinkel VS, Soechting JF. Terzuolo CA. Response to transient disturbances during intentional forearm flexion in man. Brain Res 1978; 150: 103-115.

4. Hallett M, Marsden CD. Ballistic flexion movements of the human thumb. J Physiol 1979; 294: 33-50.

5. Cooke JD. The role of stretch reflexes during active movements. Brain Res 1980; 181: 493-497.

6. Lee RG, Lucier GE. Interaction between sensory input and motor output during rapid learned movements in man. Electroenceph clin Neurophysiol 1982; suppl 36: 422-429.

7. Hallett M. Shahani BT. Young RR. EMG analysis of stereotyped voluntary movements in man. J Neurol Neurosurg Psychiat 1975: 38: 1154-1162.

8. Freund $\mathrm{HJ}$, Budingen $\mathrm{HJ}$. The relationship between speed and amplitude of the fastest voluntary contractions of human arm muscles. Exp Brain Res 1978; 31: 1-12.

9. Brown SHC, Cooke JD. Amplitude and instruction dependent modulations of movement related electromyogram activity in humans. J Physiol 1981; 316: 97-107.

10. Meinck H-M, Benecke R, Meyer W, et al. Human ballistic finger flexion: uncoupling of the three-burst pattern. Exp Brain Res 1984; 55: 127-133.

11. Lestienne F. Effects of inertial load and velocity on the braking process of voluntary limb movements. Exp Brain Res 1979; 35: 407-418.
12. Benecke R, Meinck H-M, Conrad B. Rapid goal-directed elbow flexion movements: limitations of the speed control system due to neural constraints. Exp Brain Res 1985; 59: 470-477.

13. Megaw ED. Possible modification to a rapid ongoing programmed manual response. Brain Res 1974:71: 425-442.

14. Bizzi E, Dev P, Morasso Y, Polit A. The effects of load disturbances during centrally initiated movements. J Neurophysiol 1978; 41 : 542-556.

15. Marsden W, Merton PA, Morton HB. Is the human stretch reflex cortical rather than spinal? Lancet 1973: 1: 759-761.

16. Lee RG, Tatton WG. Motor responses to sudden limb displacements in primates with specific CNS lesions and in human patients with motor system disorders. Canad J Neurol Sci 1975: 2: 285-293.

17. Day BL, Marsden CD. Accurate repositioning of the human thumb against unpredictable dynamic loads is dependent upon peripheral feedback. J Physiol 1982; 327: 393-407.

18. Brown SHC, Cooke JD. Responses to force perturbations preceding voluntary human arm movements. Brain Res 1981; 220: 350-353.

19. Mortimer JA, Webster DD, Duckich TG. Changes in short and long-latency stretch responses during the transition from posture to movement. Brain Res 1981; 229: 337-351.

20. Day BL, Rothwell JC. Marsden CD. Interaction between the longlatency stretch reflex in voluntary electromyographic activity prior to a rapid voluntary motor reaction. Brain Res 1983; 270 : 55-62.

21. Eccles JC, Eccles RM, Lundberg A. Synaptic actions on motoneurons caused by impulses in Golgi tendon organ afferents. J Physiol (London) 1957; 138: 227-252.

22. Burke D, Hagbarth KE. Lofstedt L. Muscle spindle activity in man during shortening and lengthening contractions. J Physiol 1978; 277: 131-142.

23. Prochazka A, Stephens JA. Wand P. Muscle spindle discharges in normal and obstructed movements. J Physiol 1979: 287: 57-66. 